\title{
Intracellular Regulators of Neuronal Sprouting: II. Phosphorylation Reactions in Isolated Growth Cones
}

\author{
Carolyn Hyman a and Karl H. Pfenninger \\ Department of Anatomy and Cell Biology, Columbia University, College of Physicians and Surgeons, New York, New York \\ 10032
}

\begin{abstract}
Mechanisms potentially involved in the regulation of neurite growth were investigated. Since both the phosphatidylinositol (PI) pathway and protein kinase $\mathrm{C}$ have been implicated in transmembrane signal transduction, protein and lipid phosphorylation reactions were examined in intact growth cone particles (GCPs) isolated from fetal rat brain. Three major substrates of $\mathrm{Ca}^{2+}$-dependent phosphorylation were observed: proteins of 40 and $46 \mathrm{kDa}$ and an acidic $80 \mathrm{kDa}$ species separated in 2D PAGE (pp40, pp46, and pp80ac). The pp40 and pp80ac substrates had similar rates of ${ }^{32} \mathrm{P}$ incorporation, whereas that of pp46 was more rapid. The importance of protein kinase $C$ in growth cone function is indicated by the enhancement of phosphorylation of the 3 major substrates by the phorbol ester 12-O-tetradecanoylphorbol 13-acetate (TPA). An examination of the $\mathrm{Ca}^{2+}$-dependent ${ }^{32} \mathrm{P}$ incorporation into pp40 and pp46 revealed serine to be the only amino acid phosphorylated under these conditions. A rapidly metabolized pool of phosphoinositides was observed in GCPs. This suggests the presence of the PI pathway's enzymes in this fraction. Inositol trisphosphate $\left(\mathrm{IP}_{3}\right)$ was found to stimulate the phosphorylation of pp40 and pp80ac, indicating a possible link between the activation of the PI pathway and protein phosphorylation. Our findings demonstrate the prominence of the PI pathway and of $\mathrm{Ca}^{2+}$ dependent protein phosphorylation in the growth cone and may suggest the involvement of these mechanisms in growthfactor signal transduction.
\end{abstract}

Extension of the neurite, with a growth cone at its leading edge, is a major feature of neuronal differentiation. Directed neurite growth is likely to be controlled by growth factors and their corresponding signal transduction systems. NGF, acting on certain peripheral neurons, is the best understood neurotrophic factor (Greene and Shooter, 1980). It is known to act exclusively on the distal neurite (Campenot, 1977), but the nature of its signal transducing system remains unclear. NGF has been observed to activate phospholipid transmethylation in peripheral

\footnotetext{
Received Dec. 29, 1986; revised May 15, 1987; accepted May 21, 1987.

We thank Linda B. Friedman for her skilled technical assistance and Ruth Carpino for help in preparation of the manuscript. We also wish to acknowledge gratefully Dr. Donald Mills' assistance with the phosphoamino acid determinations. This research was supported by a Muscular Dystrophy Association Postdoctoral Fellowship to C.IH. and grants from the Stifel Paralysis Research Foundation and the NIH (NS 21729 ) to K.H.P.

Correspondence should be addressed to Karl H. Pfenninger, Department of Cellular and Structural Biology, University of Colorado School of Medicine, Denver, CO 80262 .

a Present address: NYU Medical Center, Department of Cell Biology, 550 First Avenue, New York, NY 10016.

Copyright (C) 1987 Society for Neuroscience $0270-6474 / 87 / 124076-08 \$ 02.00 / 0$
}

nerve growth cones (Pfenninger and Johnson, 1981); this enzyme activity has also been detected in growth cone fragments, called growth cone particles (GCPs) (Pfenninger et al., 1983), isolated by subcellular fractionation from fetal rat brain (Garofalo and Pfenninger, 1984). Further, increased polyphosphoinositide metabolism (Lakshmanan, 1978; Traynor, 1984) and protein kinase C activity (Hama et al., 1986) appear to be involved in the NGF stimulation of $\mathrm{PC} 12$ cells or sympathetic neurons. Changes in the intracellular concentration of calcium ion have been implicated in the control of growth cone motility (Anglister et al., 1982) and of the growth cone's chemotactic response to NGF (Gundersen and Barrett, 1980). Calmodulin and a series of developmentally regulated calmodulin-binding proteins have been found in GCPs (Hyman and Pfenninger, 1985). Also, both $\mathrm{Ca}^{21} /$ calmodulin-dependent and $\mathrm{Ca}^{2+} /$ phospholipid-dependent protein kinase activities are very prominent in GCPs (Katz et al., 1985). These observations are consistent with results obtained in numerous other systems, which have implicated both protein kinase C (Kikkawa et al., 1982; Nishizuka, 1984a) and the phosphorylation and breakdown of phosphatidylinositol (PI) (Williamson et al., 1985) in the transduction of cell surface signals. $\mathrm{Ca}^{2+} /$ calmodulin-dependent kinase (cf. Bennet et al., 1983; Kennedy, 1983; Kennedy et al., 1983) has also been associated with external signal transduction (Nestler et al., 1984). Such kinase activities could be involved in a variety of mechanisms regulating growth cone motility, membrane expansion, and signaling to the perikaryon. Growth factor signal transduction systems in different neuron classes may be similar, although the receptors activating them are likely to be different. In this regard, it is reasonable to suggest that the effects of (putative) growth-promoting activities on CNS neurons are likely to resemble those of NGF on peripheral neurons.

In the absence of a CNS growth factor, we have focused the present study on (1) the further characterization of calciumdependent phosphorylation reactions as they occur in GCP preparations in which cellular compartments are left intact, and (2) the description of other potential elements of a growth-factor-activated signal transduction system. Evidence is presented that implicates the PI pathway in the regulation of the growth cone's major protein kinases.

\section{Materials and Methods}

Materials. $\gamma^{32} \mathrm{P}$-adenosine triphosphate $\left(\gamma^{32} \mathrm{P}\right.$-ATP) was obtained from ICN Radiochemicals. Bovine brain calmodulin (CM), inositol trisphosphate $\left(\mathrm{IP}_{3}\right.$ ), phosphatidylserine (PS), 1,3-diolein (D), saponin, phosphoserine (P-Ser), phosphotyrosine (P-Tyr), phosphothreonine (P-Thr), phosphatidylinositol 4-monophosphate (PIP), and phosphatidylinositol 4,5-bisphosphate $\left(\mathrm{PIP}_{2}\right)$ were obtained from Sigma Chemical Co. The calcium ionophore A23187 was purchased from Calbiochem. 12-O- 
Tetradecanoylphorbol 13-acetate (TPA) was the generous gift of Dr. Bernard Weinstein of Columbia University, College of Physicians \& Surgeons, New York, NY. Other reagents and chemicals, all reagent grade, were from Fisher.

\section{Methods}

Preparation of growth cone particles. GCPs were prepared according to the method of Pfenninger et al. (1983), separated from soluble contaminants on a column of controlled-pore glass, and concentrated as described, with modifications detailed by Hyman and Pfenninger (1985). These GCP preparations were used immediately.

Calcium-stimulated phosphorylation. The reaction mixture, in a final volume of $100 \mu$, contained: $10 \mathrm{~mm}$ HEPES (pH 7.2), $120 \mathrm{~mm} \mathrm{KCl,} 12$ $\mathrm{mm} \mathrm{NaCl}, 1.62 \mathrm{~mm} \mathrm{MgSO}_{4}, 0.4 \mathrm{~mm}$ EGTA, $0.7 \mathrm{~mm} \mathrm{CaCl}_{2}, 0.01$ or $0.02 \%$ saponin, $60-90 \mu \mathrm{g} \mathrm{GCP}$ protein, and $5 \mu \mathrm{m} \gamma^{32} \mathrm{P}-\mathrm{ATP}(25 \mathrm{Ci} /$ $\mathrm{mmol}$ ). GCPs were equilibrated on ice with buffer and saponin, then warmed to $30^{\circ} \mathrm{C}$ for $1 \mathrm{~min}$. Reaction was initiated by the simultaneous addition of $\gamma^{32}$ P-ATP and $\mathrm{CaCl}_{2}$, and the samples were incubated at $30^{\circ} \mathrm{C}$ for the specified time. The reaction was terminated by the addition of Laemmli $3 \times$ sample buffer or, for samples intended for 2D PAGE, by addition of $11 \mu \mathrm{l} 50 \%$ mercaptoethanol and $20 \% \mathrm{NP}-40$.

Phosphoamino acid analysis. Phosphorylated proteins of interest were excised from 5-15\% acrylamide gels (cf. Laemmli, 1970), electroeluted through $5 \%$ acrylamide tube gels $(90 \mathrm{~mm}$ long, $3 \mathrm{~mm}$ diameter), and collected in dialysis bags attached to the bottom of the tube gels. These dialysis bags contained a small volume of $0.025 \mathrm{~mm}$ Tris and $0.192 \mathrm{M}$ glycine, $\mathrm{pH}$ 8.3. Electroelution was carried out at $10 \mathrm{~mA} /$ tube gel for 1.5-2 hr.

Recovery and processing of the electroeluted protcins for acid hydrolysis were carried out using a method similar to that of Rees-Jones and Taylor (1984). The protein solutions were dialyzed overnight in a large volume of $100 \mathrm{~mm}$ HEPES containing $0.05 \%$ SDS (pH 7.6) at $4^{\circ} \mathrm{C}$. The dialyzed proteins, adjusted to $0.5 \mathrm{mg} / \mathrm{ml} \mathrm{BSA}$ carrier, were then acetone-precipitated at $-15^{\circ} \mathrm{C}$, and the precipitates washed extensively with $-15^{\circ} \mathrm{C}$ acetone. The washed precipitates were then brought up in $0.5 \mathrm{ml} 6 \mathrm{~N} \mathrm{HCl}$, and incubated in boiling water for $1 \mathrm{~min}$ to insure solubilization. The solution was then sealed under $\mathrm{N}$, and incubated at $110^{\circ} \mathrm{C}$ for $2 \mathrm{hr}$. Following acid hydrolysis, the sample was dried down and the residue brought up to $200 \mu \mathrm{l} \mathrm{H}_{2} \mathrm{O}$. Following roto-evaporation and a second $\mathrm{H}_{2} \mathrm{O}$ wash, the residue was finally brought up in $20 \mu \mathrm{l} \mathrm{H}_{2} \mathrm{O}$ containing $0.2 \mathrm{mg} / \mathrm{ml}$ P-Ser, P-Thr, and P-Tyr. Samples were spotted on Whatman $3 \mathrm{M}$ paper, and high-voltage paper electrophoresis was carricd out in pyridinc-acetate buffer, $\mathrm{pH} \mathrm{3.5,} \mathrm{at} 2000 \mathrm{~V}$ for $1 \mathrm{hr}$ (Cheng and Chen, 1981). The chromatogram was autoradiographed and the standards detected by ninhydrin staining.

Analysis of phosphorylated lipids. Following phosphorylation incubations, reactions were terminated by addition of $2: 1$ ( $\mathrm{vol} / \mathrm{vol})$ chloroform-methanol. Extraction and thin-layer chromatography were carried out according to Sugimoto et al. (1984). For some experiments, extracted lipid was brought up in Laemmli sample buffer and applied to $5-15 \%$ acrylamide gradient gels. Following electrophoresis, the gels were dried and autoradiographed.

Electrophoresis procedures. Laemmli SDS-PAGE was carried out as described previously (Hyman and Pfenninger, 1985). Two-dimensional nonequilibrium $\mathrm{pH}$-gradient gel electrophoresis (NEPHGE) was carried out according to the method of O'Farrell et al. (1977), with the modifications described by Ellis et al. (1985). Molecular weights were calibrated using the following standard proteins: myosin $(210,000), \beta$-galactosidase $(116,000)$, phosphorylase B $(94,000)$, BSA $(68,000)$, ovalbumin $(43,000)$, carbonic anhydrase $(30,000)$, soybean trypsin inhibitor $(20,000)$, and lysozyme $(14,400)$. Coomassie blue was used to stain gels (Fairbanks et al., 1971); destaining was performed according to the method of Weber and Osborn (1969). Autoradiography of dried gels was carried out with Kodak X-Omat film at $-80^{\circ} \mathrm{C}$, using intensifier screens, for the indicated exposure times.

Miscellaneous procedures. Protein was assayed by the method of Bradford (1976) or Lowry (1951) (using BSA as a standard). Quantitation of ${ }^{32} \mathbf{P}$ incorporation into individual proteins was performed by excision of the protein band from the gel, solubilization with Protosol (New England Nuclear), and subsequent liquid-scintillation counting.

\section{Results}

A meaningful examination of the endogenous phosphorylation reactions occurring in growth cones necessitates the isolation of a population of sealed GCPs in order to prevent the loss of important enzymatic cofactors and the mixing of cytoplasmic compartments. GCPs, prepared as described in Methods, were tested for their degree of membrane integrity, as shown in Figure $1 A$. GCPs were incubated with $\mathrm{Ca}^{2+}$ and $\gamma^{32} \mathrm{P}$-ATP in the presence or absence of $0.02 \%$ saponin. Thereafter, the proteins were separated by SDS-PAGE, the gel was dried, and an autoradiogram prepared. In the presence of saponin, 3 major phosphoprotein bands of 80,46 , and $40 \mathrm{kDa}$ are observed. By contrast, in the absence of saponin, virtually no reaction products are detected, indicating that $\gamma^{32}$ P-ATP does not have access to the GCPs' interior. This evidence of the integrity of GCPs indicates that our preparation is suitable for a study of endogenous growth cone phosphorylation reactions.

\section{$\mathrm{Ca}^{2+}$-dependent protein kinase activity}

The calcium-dependent nature of ${ }^{32} \mathrm{P}$ incorporation into the 80 , 46 , and $40 \mathrm{kDa}$ substrates is demonstrated in Figure $1 B$. Phosphorylation of saponin-permeabilized GCPs was carried out as described in Methods in the absence and presence of $0.3 \mathrm{~mm}$ free $\mathrm{Ca}^{2+}$. The autoradiogram of the SDS gel and subsequent quantitation of ${ }^{32} \mathrm{P}$ incorporation into the major substrates show the phosphorylation of the 40 and $80 \mathrm{dKa}$ substrates to be stimulated roughly 2-fold by $\mathrm{Ca}^{2+}$, and that of the $46 \mathrm{kDa}$ substrate to be increased by a factor of 4 . The phosphoprotein at $52 \mathrm{kDa}$ is likely to be tubulin (Katz et al., 1985). [This protein has been shown to comigrate in $2 \mathrm{D}$ gels with purified tubulin and to react with an anti- $\beta$-tubulin antibody (P. Simkowitz, L. Ellis, and K. H. Pfenninger, unpublished observations)]. The phosphorylation of this protein is not stimulated by the presence of calcium ion in these experiments.

The time course of $\mathrm{Ca}^{2+}$-stimulated ${ }^{32} \mathrm{P}$ incorporation into saponin-permeabilized GCPs was examined next. Figure 2 shows the quantitation of the calcium-dependent phosphorylation of the major GCP substrates as a function of time. The calciumdependent ${ }^{32} \mathrm{P}$ incorporation was calculated as the difference between ${ }^{32} \mathrm{P}$ incorporation in the presence of $0.3 \mathrm{~mm}$ free $\mathrm{Ca}^{2+}$ and that occurring in the (nominal) absence of free $\mathrm{Ca}^{2+}$. The 40 and $80 \mathrm{kDa}$ substrates have quite comparable time courses of phosphorylation; the rate of ${ }^{32} \mathrm{P}$ incorporation is relatively slow at first, but increases during the $40-\mathrm{sec}$ observation time. In contrast, the onset of phosphorylation of the $46 \mathrm{kDa}$ protein is immediate and rapid, but ${ }^{32} \mathbf{P}$ incorporation slows down to approach saturation after $20 \mathrm{sec}$ of reaction time. Calciumstimulated phosphorylation of tubulin was observed only at the longest incubation time point $(70 \mathrm{sec})$. The finding of differential onsets and rates of phosphorylation of these substrates may suggest the presence of different calcium-dependent protein kinases in GCPs.

A previous study has shown the presence of 2 discrete calcium-dependent protein kinase activities in GCPs (Katz et al., 1985). By the addition of exogenous calmodulin, a $\mathrm{Ca}^{21} / \mathrm{CM}$ dependent kinase was demonstrated to phosphorylate the 46 $\mathrm{kDa}$ protein and a basic $80 \mathrm{kDa}$ GCP protein identified as synapsin I. Similarly, the addition of PS/D in the presence of Triton X-100 was shown to enhance the incorporation of ${ }^{32} \mathrm{P}$ into the 40 and acidic $80 \mathrm{kDa}$ species (pp40 and pp80ac) by a kinase with the properties of protein kinase C. Protein kinase $\mathrm{C}$ is known to be stimulated by the tumor-promoting phorbol ester TPA (Castagna et al., 1982). It was, therefore, of interest to determine which substrates showed increased phosphorylation as a result of TPA stimulation in the saponin-permeabilized 


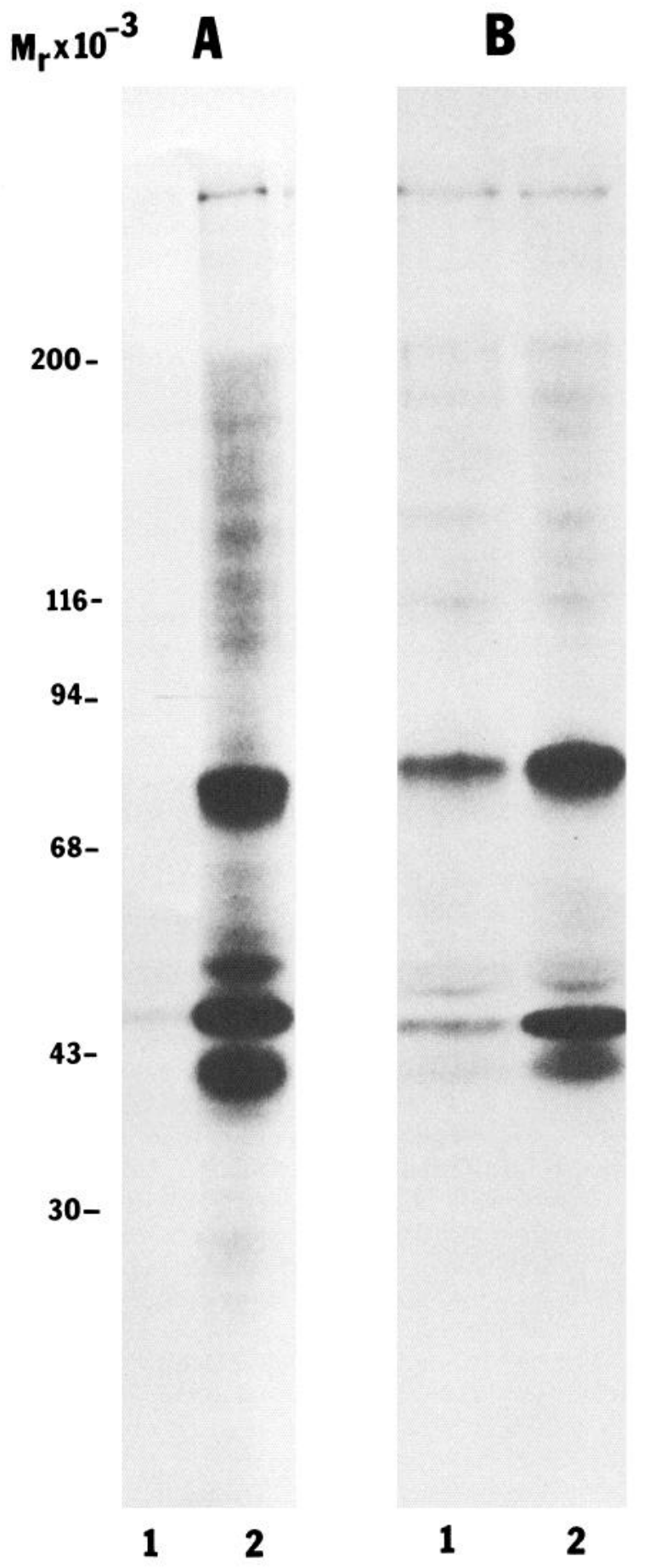

Figure 1. Major calcium-dependent protein kinase substrates of GCPs. $A$, Autoradiographic exposure of phosphoproteins of sealed and saponin-permeabilized GCPs separated by SDS-PAGE. GCPs $(100 \mu \mathrm{g})$ were phosphorylated in the absence (lane 1) or presence (lane 2) of $0.02 \%$ saponin. Reactions were carried out in the presence of $0.3 \mathrm{~mm}$ free $\mathrm{Ca}^{2+}$ for $20 \mathrm{sec}$, as described in Methods. The positions of molecular-weight standards are indicated by dashes. B. Autoradiography of phosphoproteins of saponin-permeabilized GCPs separated by SDS-PAGE. GCPs $(100 \mu \mathrm{g})$ were phosphorylated in the absence of free $\mathrm{Ca}^{2+}(0.4 \mathrm{~mm}$ EGTA, lane I) or $0.3 \mathrm{~mm}$ free $\mathrm{Ca}^{2+}$ (lane 2), as described in Methods. SDSPAGE and quantitation of ${ }^{32} \mathrm{P}$ incorporation into individual protein bands was carried out as described in Methods. The incorporation of ${ }^{32} \mathrm{P}$ into major GCP substrates under the 2 conditions is as follows (in $\mathrm{cpm}$ ): $80 \mathrm{kDa}$-lane 1, 670, lane 2, 1485; $52 \mathrm{kDa}$-lane 1, 296, lane 2, $331 ; 46 \mathrm{kDa}$-lane 1, 333, lane 2, 1200; $40 \mathrm{kDa}$-lane 1, 289, lane 2, 551 .

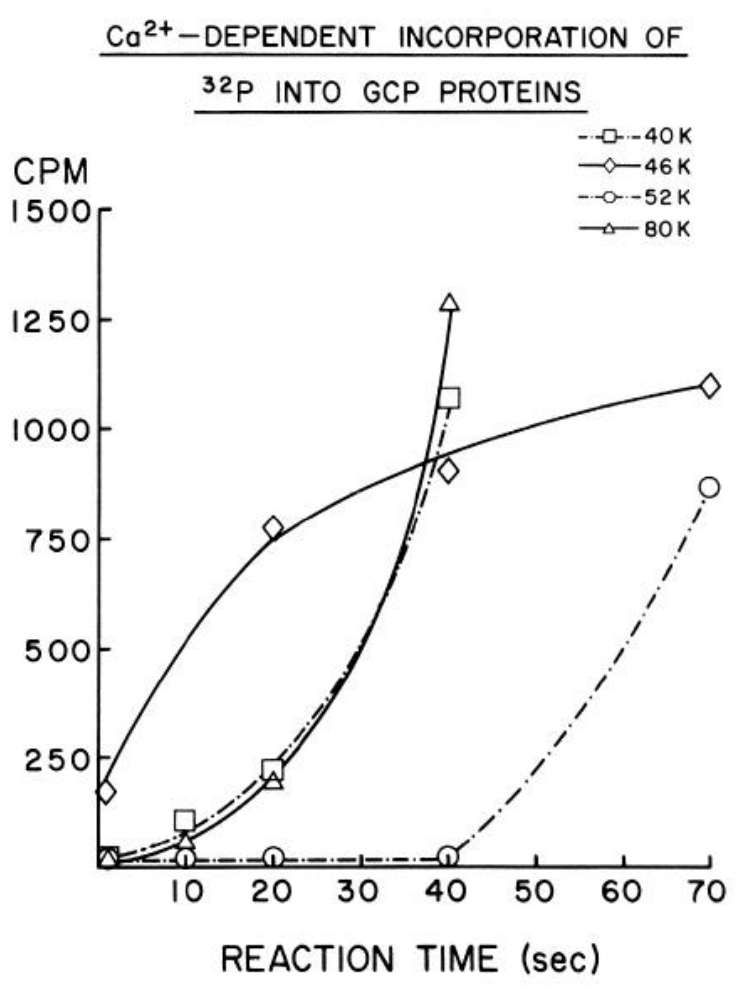

Figure 2. Time course of $\mathrm{Ca}^{2+}$-stimulated ${ }^{32} \mathrm{P}$ incorporation into saponin-permeabilized GCPs. GCPs were phosphorylated in the presence of $0.4 \mathrm{~mm}$ EGTA or $0.3 \mathrm{~mm}$ free $\mathrm{Ca}^{2+}$ for the specified times at $30^{\circ} \mathrm{C}$. Following SDS-PAGE, the phosphoproteins were excised and counted. Calcium-stimulated ${ }^{32} \mathrm{P}$ incorporation is calculated as the difference between the counts incorporated in the presence of $0.3 \mathrm{mM}$ free $\mathrm{Ca}^{2+}$ and those incorporated in the presence of $0.4 \mathrm{~mm}$ EGTA.

GCP system. Shown in Figure 3 are autoradiograms of 2D NEPHGE gels of GCPs phosphorylated in the presence of 0.3 mM free $\mathrm{Ca}^{2+}$ without $(A)$ or with $(B)$ the addition of $4 \mu \mathrm{g} / \mathrm{ml}$ TPA. In these conditions, Figure $3 A$ shows primarily the substrates of $\mathrm{Ca}^{2+} / \mathrm{CM}$-dependent kinase, and Figure $3 B$ shows, in addition, C-kinase substrates. ${ }^{32} \mathrm{P}$ incorporation into the basic $80 \mathrm{kDa}$ substrate, identified as synapsin I (Fig. 3, arrow), is not enhanced by the addition of TPA, nor is the phosphorylation of the $52 \mathrm{kDa}$ protein (believed to be tubulin) increased. However, ${ }^{32} \mathrm{P}$ incorporation into other proteins is stimulated by TPA, as indicated by quantitative analysis (data not shown): for $\mathrm{pp} 40$ and pp46 (Fig. 3, arrowheads), the increase is 2-fold, whereas for pp80ac (arrowhead) we find a 3-fold enhancement. One can identify pp 46 on the basis of its electrophoretic mobility relative to pp40 and the putative tubulin complex, of its typical microheterogeneity (Katz et al., 1985), and of its phosphopeptide map (not shown; cf. Katz et al., 1985). Numerous other, minor GCP substrates exhibit increased phosphorylation due to TPA; they include a group of 3 proteins in the molecularweight range of $29-31 \mathrm{kDa}$. This result shows pp 40 and pp $80 \mathrm{ac}$, substrates of the $\mathrm{Ca}^{2+} /$ phospholipid dependent kinase (Katz et al., 1985), to have enhanced ${ }^{32} \mathrm{P}$ incorporation in the presence of TPA. In addition, phosphorylation of pp46, a substrate of $\mathrm{Ca}^{2+} / \mathrm{CM}$-dependent kinase (Katz et al., 1985), is also stimulated in the presence of TPA.

\section{Phosphoamino acids}

In light of evidence linking tyrosine kinases and growth-control processes (Ushiro and Cohen, 1980; Pike et al., 1983; Frackelton 


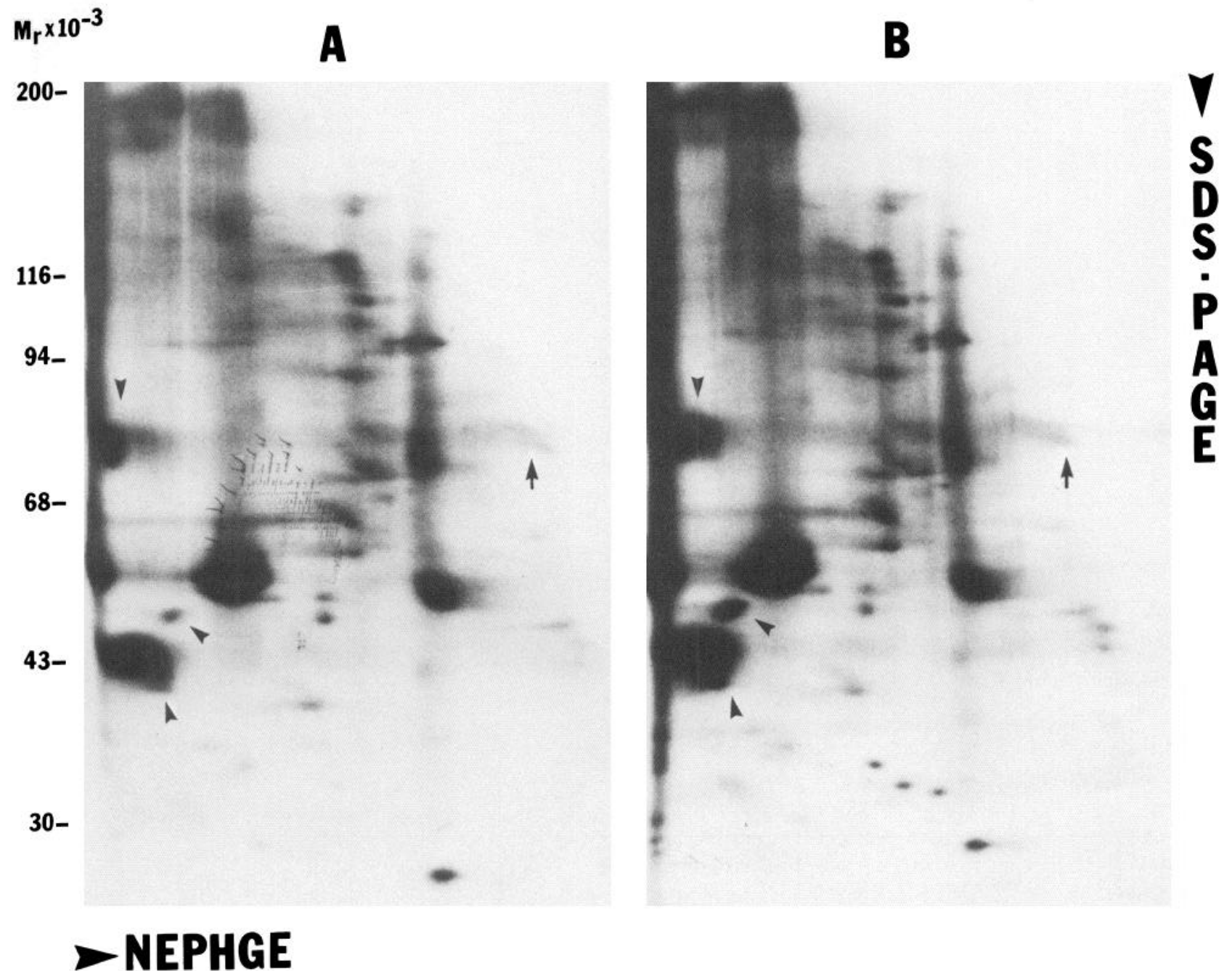

Figure 3. Analysis of phorbol ester stimulation of GCP phosphorylation by 2D nonequilibrium pH-gradient gel electrophoresis (NEPHGE). A, Autoradiogram of GCP proteins $(100 \mu \mathrm{g})$ phosphorylated in the presence of $0.3 \mathrm{~mm}$ free $\mathrm{Ca}^{2+}$ and separated by $2 \mathrm{D}$ NEPHGE. $B$, Autoradiogram of GCP proteins $(100 \mu \mathrm{g})$ phosphorylated in the presence of $0.3 \mathrm{~mm}$ free $\mathrm{Ca}^{2+}$ and $4 \mu \mathrm{g} / \mathrm{ml} \mathrm{TPA}$. Major substrates whose phosphorylation is stimulated are indicated by arrowheads. The position of a basic substrate of approximately $80 \mathrm{kDa}$, tentatively identified as synapsin I, is indicated by an arrow. The $\mathrm{pH}$ range resolved in the first dimension spans approximately $\mathrm{pH} 4.0$ (left) to 9.5 (right). The positions of molecular-weight standards are indicated on the left.

et al., 1984; Hirata et al., 1984; Nemenoff et al., 1984; Petruzzelli et al., 1984; Rees-Jones et al., 1984), it is of interest to study the identity of the phosphorylated amino acid residues of the 40 and $46 \mathrm{kDa}$ substrates. The results of this determination are shown in Figure 4. GCPs were phosphorylated in the presence of $0.3 \mathrm{mM}$ free $\mathrm{Ca}^{2+}$ under the standard reaction conditions, and the individual substrates were isolated as described in Materials and Methods. High-voltage paper electrophoresis of acid hydrolysates of pp 40 and pp46 was undertaken to resolve P-Ser, P-Thr, and P-Tyr. The autoradiogram of such a chromatogram shows only P-Ser in both substrates. Thus, it is unlikely that a tyrosine kinase phosphorylates these proteins under the experimental conditions used.

\section{Phospholipid phosphorylation}

A close examination of phosphorylated substrates of GCPs by SDS-PAGE reveals a diffuse radiolabeled band that migrates below the dye front (Fig. 5A, arrowhead). The unusual electrophoretic mobility of this ${ }^{32} \mathrm{P}$-labeled material suggests that it is a lipid substrate for phosphorylation in GCPs. For this reason, the lipid phosphorylation products of GCPs were examined. Growth cone particles were phosphorylated under the standard conditions, and the reaction was terminated by the addition of chloroform-methanol, 2:1 (vol/vol). Following extraction, thinlayer chromatography showed ${ }^{32} \mathrm{P}$ incorporation into spots comigrating with phosphatidic acid (PA) and/or PI, PIP, and PIP (Fig. $5 B$ ). When phosphorylated lipid extracts of GCPs are dried under $\mathrm{N}_{2}$, resuspended, and run on SDS-PAGE, the electrophoretic mobility of the lipid is observed to be identical to that of the diffuse ${ }^{32} \mathrm{P}$-labeled band seen in polyacrylamide gels of phosphorylated GCPs (Fig. 5A, lane 2). This evidence indicates that GCPs contain the enzymes necessary for the phosphorylation of PI, which, in part, comprise the PI pathway.

\section{Inositol phosphate and protein phosphorylation}

If the PI pathway were to function in GCPs as part of a $\mathrm{Ca}^{2+}$ triggering system, then $\mathrm{IP}_{3}$, recently shown to be involved in releasing calcium from nonmitochondrial intracellular stores 


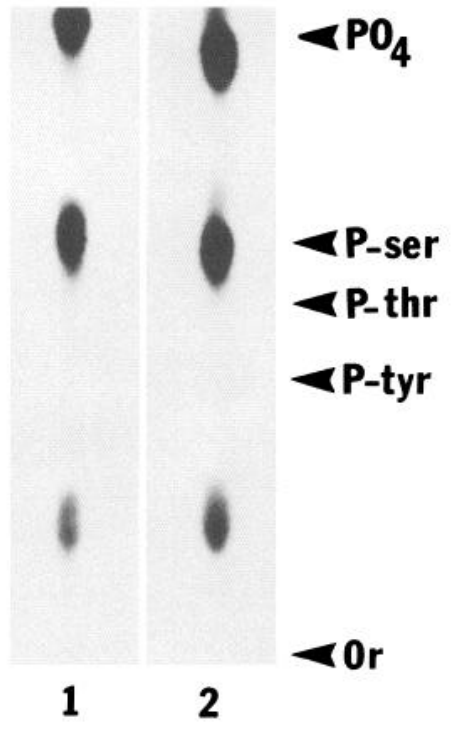

Figure 4. Phosphoamino acid analysis of pp40 and pp46. SDS-PAGE was carried out with $750 \mu \mathrm{g}$ GCPs phosphorylated in the presence of $0.3 \mathrm{~mm}$ free $\mathrm{Ca}^{2+}$. Both pp40 and pp46 were excised and electroeluted. Sample preparation and separation of phosphoamino acids by highvoltage paper chromatography were performed as described in Methods. The autoradiogram of the chromatogram was exposed for $24 \mathrm{hr}$. Lane 1, pp40 digest; lane 2, pp46 digest. The positions of standard P-Ser, $\mathrm{P}-\mathrm{Thr}$, and P-Tyr are indicated on the right. Or, Origin.

(Streb et al., 1983; Gershengorn et al., 1984; Joseph et al., 1984; Sureshk et al., 1984; O'Rourke et al., 1985), would be expected to have an effect on calcium-dependent phosphorylation in GCPs. This possibility was studied by carrying out phosphorylation reactions in saponin-treated GCPs in the presence or absence of exogenous $\mathrm{IP}_{3}$. The effect of $\mathrm{IP}_{3}$ on protein phosphorylation was also examined in GCPs whose internal calcium stores had been depleted by pretreatment with the $\mathrm{Ca}^{2+}$ ionophore $\mathrm{A} 23187$. Phosphorylated proteins were separated by SDS-PAGE, localized by autoradiography, and cut out of the gels for liquidscintillation counting. Values for ${ }^{32} \mathrm{P}$ incorporation into protein bands of 80,52 (presumably tubulin), 46 , and $40 \mathrm{kDa}$ were normalized for each band. This was done by the arbitrary assignment of $100 \%$ incorporation to that labeling observed in GCPs with free $\mathrm{Ca}^{2+}$ buffered at $1 \mu \mathrm{M}$ in the absence of exogenous $\mathrm{IP}_{3}$. Mean counts of 3 independent experiments (performed in duplicate) \pm SDs (error bars) are shown in Figure 6. Exogenous $\mathrm{IP}_{3}$ stimulated the incorporation of ${ }^{32} \mathrm{P}$ into proteins of 80 and $40 \mathrm{kDa}$. Student's $t$ test showed experimental values to be different from controls at a probability level of $p<0.05$. However, no effect was observed on the phosphorylation of pp 46 or (putative) tubulin. In GCPs pretreated with A23187 to deplete internal calcium stores, there was no evidence for $\mathrm{IP}_{3}$ stimulation of protein phosphorylation.

\section{Discussion}

In light of the implication of the PI pathway (Davis et al., 1984; Watson et al., 1984; Yano et al., 1984; Williamson et al., 1985) and protein kinase C (Drust and Martin, 1984; Nishizuka, 1984a; Vilgrain et al., 1984; Fearon and Tashjian, 1985) in transmembrane signaling, both protein and lipid phosphorylation reactions were examined in GCPs. Morphological and biochemical evidence strongly supports the view that the GCP fraction is indeed largely composed of growth cone-derived elements (for

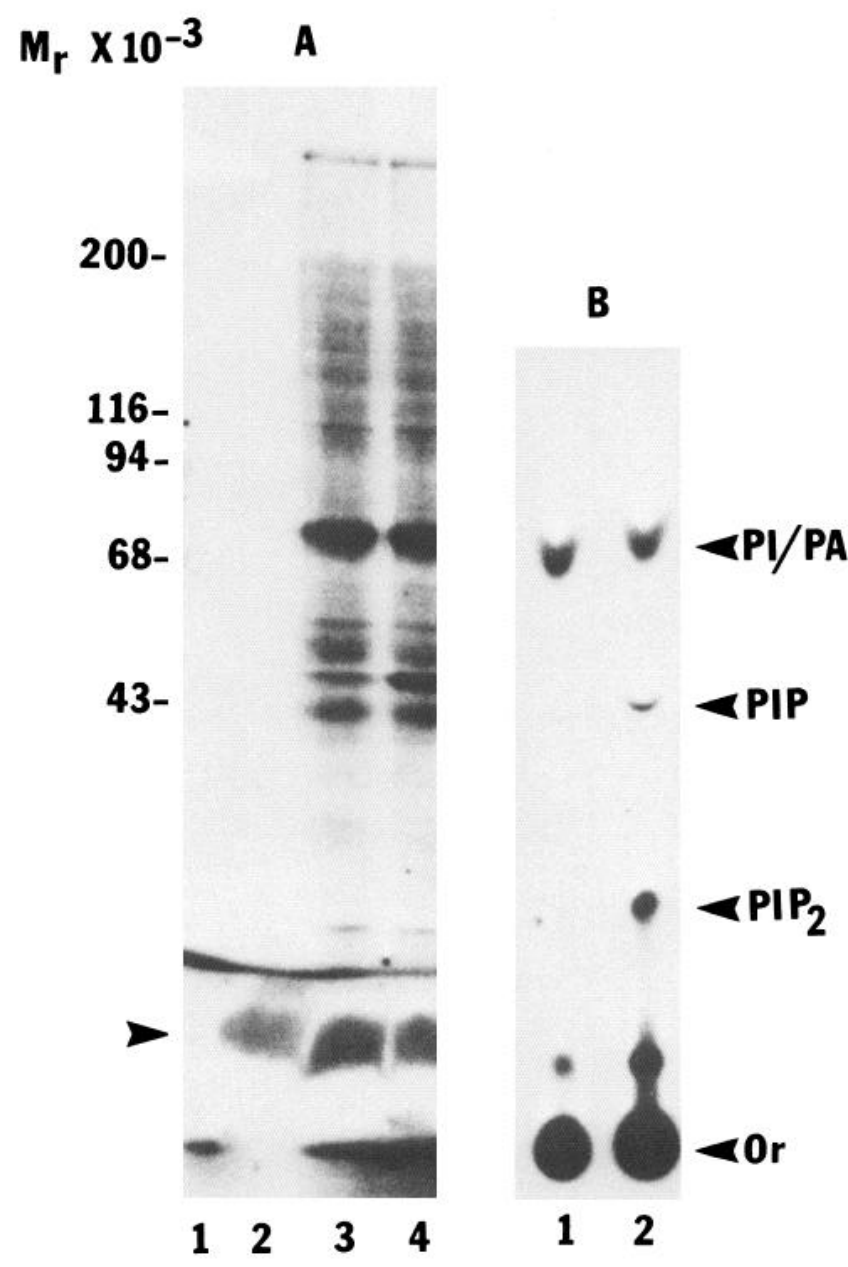

Figure 5. Lipids phosphorylated in GCPs. A, Autoradiogram of an SDS gel of GCPs $(100 \mu \mathrm{g})$ phosphorylated in the absence of free $\mathrm{Ca}^{2+}$ (lane 3 ) or the presence of $0.3 \mathrm{~mm}$ free $\mathrm{Ca}^{2+}$ (lane 4). Shown for comparison in lane 1 is $\gamma^{32} \mathrm{P}$-ATP. Lane 2 contains a lipid extract prepared from GCPs phosphorylated in the presence of $0.3 \mathrm{~mm}$ free $\mathrm{Ca}^{2+}$ (arrowhead). The positions of the molecular-weight standards are indicated on the left. B, Autoradiographic exposure of a thin-layer chromatogram of lipids extracted from phosphorylated GCPs with chloroform-methanol. Lane 1 contains a lipid extract of GCPs phosphorylated in the absence of free $\mathrm{Ca}^{2+}$; lane 2 contains a similar extract of GCPs phosphorylated in the presence of $0.3 \mathrm{mM} \mathrm{Ca}^{2+}$. The positions of standard PA, PI, PIP, and $\mathrm{PIP}_{2}$ are indicated on the right. Or, Origin.

a recent discussion of this issue, see Pfenninger, 1986). However, the GCPs isolated from whole fetal brain derive from a heterogeneous neuron population and are, like all subcellular fractions, contaminated to some degree by other elements. Therefore, this study can focus only on the predominant components of growth cones - those shared by their majority.

The analysis of a complex signal transduction cascade required a GCP system that remained sealed throughout the fractionation in order to eliminate artifacts due to depletion of any intrinsic factors necessary for kinase activity and/or due to mixing of cytoplasmic compartments. The GCPs, isolated as described above, are sealed on the basis of their ability to exclude $\gamma^{32} \mathrm{P}$-ATP. Such GCPs take up ${ }^{32} \mathrm{P}$ as orthophosphate and incorporate it into ATP and protein (data not shown). However, our studies on protein and lipid phosphorylation necessitated high levels of radiolabeling, a short time scale, and well-defined conditions; thus, the experiments were carried out with $\gamma^{32} \mathrm{P}$ - 


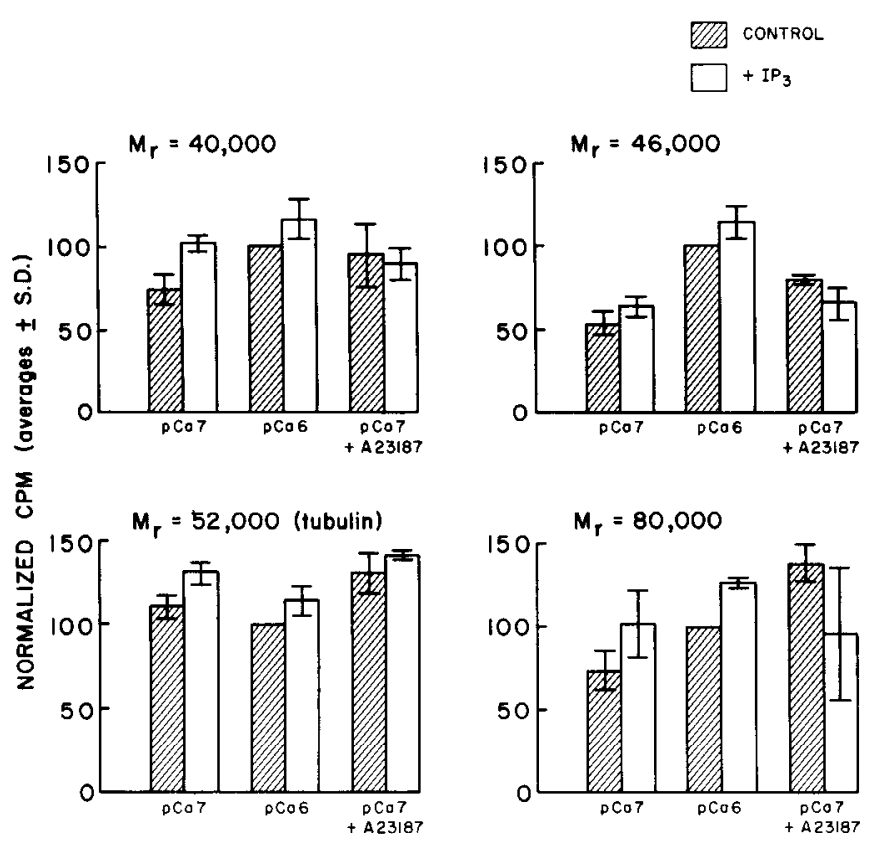

Figure 6. IP 3 stimulation of GCP phosphorylation. Growth cone particles were phosphorylated in the presence of $0.01 \%$ saponin for $20 \mathrm{sec}$ with or without $1 \mu \mathrm{M}$ inositol trisphosphate $\left(\mathrm{IP}_{3}\right)$. Free calcium was buffered to 0.1 or $1.0 \mu \mathrm{M}$, and one set of samples was pre-equilibrated in the presence of $10 \mu \mathrm{M} \mathrm{A23187.} \mathrm{Samples} \mathrm{werc} \mathrm{clecrophoresed} \mathrm{in} \mathrm{5-}$ $15 \%$ acrylamide gels. Following Coomassie staining and autoradiography, the protein bands were excised and their radioactivity assessed by liquid-scintillation counting. Values from separate experiments were normalized by assignment of $100 \%$ incorporation to GCP samples phosphorylated in the presence of $1 \mu \mathrm{M}$ free $\mathrm{Ca}^{2+}$ in the absence of $\mathrm{IP}_{3}$.

ATP. Only at the onset of the incubation with the radioactive precursor were GCPs permeabilized with a small concentration $(0.01-0.02 \%)$ of saponin, in order to allow access of the label to their interior. Saponin is believed to affect primarily the cholesterol-containing plasmalemma, and the short exposure of GCPs to saponin is likely to minimize changes in their composition.

The major $\mathrm{Ca}^{2+}$-dependent phosphorylation substrates in broken GCPs have been described previously as proteins of 40, 46, and $80 \mathrm{kDa}$ (Katz et al., 1985). This report identified both $\mathrm{Ca}^{2+}$ CM- and $\mathrm{Ca}^{2+}$-phospholipid-dependent kinase activities; pp40 and pp80ac were found to be substrates of a $\mathrm{Ca}^{2+} /$ phospholipiddependent kinase, whereas pp46 was that of a $\mathrm{Ca}^{21} / \mathrm{CM}$-dependent kinase. These kinases are active in the saponin-permeabilized system we have described, showing similar substrate specificities. However, the onset and saturation of calcium-stimulated phosphorylation of pp46 occur considerably more rapidly than those of pp40 and pp80ac. This can be explained only in part by differences in substrate and/or enzyme activity.

Phorbol esters are compounds known to activate protein kinase C (Castagna et al., 1982), and C-kinase has been proposed as the phorbol ester receptor (Kikkawa et al., 1983; Niedel et al., 1983). Several reports have detailed the effects of phorbol esters on the phosphorylation of C-kinase substrates, such as the epidermal growth factor (EGF) receptor (Davis and Czech, 1984 ) and an $80 \mathrm{kDa}$ protein of $3 \mathrm{~T} 3$ cells (Rozengurt et al., 1983). Autoradiography of GCP phosphoproteins separated by 2D PAGE shows that the phorbol ester TPA enhances phosphorylation of the previously described substrates of $\mathrm{Ca}^{2+} /$ phospholipid-dependent kinase (pp40 and pp80ac), as expected. In addition, the substrate of a $\mathrm{Ca}^{2+} / \mathrm{CM}$-stimulated kinase, pp46, also exhibits augmented phosphorylation in the presence of TPA. [The observation of TPA-stimulated pp46 phosphorylation is consistent with the results of another study of this substrate, which has shown pp46 phosphorylation to be increased by phospholipid (Nelson et al., 1985), depending on the in vitro reaction conditions (relatively high levels of Triton X-100 (0.1\%) are a prerequisite).] That the stimulation of phosphorylation by TPA is not a nonspecific phenomenon affecting all GCP phosphoproteins is shown by the absence of any effect on ${ }^{32} \mathrm{P}$ incorporation into several proteins, including a basic $80 \mathrm{kDa}$ species, identified as synapsin I. The extent to which $\mathrm{Ca} / \mathrm{CM}$-kinase and C-kinase phosphorylate pp46 in vivo cannot be assessed on the basis of the data available to us now, nor can we exclude the possibility that the effect of one of the kinases on the substrate is indirect. However, the somewhat unusual dual specificity of this substrate suggests its involvement in a complex, calciumdependent cascade, with effects converging on it and/or feeding back upon it. This view gains support from the difference in time course between phosphorylation of the C-kinase and that of the calcium/CM-kinase substrates. The apparently complex interactions of pp46 with regulatory components of the growth cone are of particular interest, in view of this protein's prominence in growth, regeneration, and plasticity. While its function is unknown, pp46 is almost certainly identical to the growthassociated protein GAP43 (Meiri et al., 1986; see also Skene et al., 1986) and to protein F1, whose phosphorylation is increased with long-term potentiation in the hippocampus (Nelson et al., 1985; Pfenninger, 1986; R. B. Nelson, A. Routtenberg, C. Hyman, and K. H. Pfenninger, unpublished observations; see also DeGraan et al., 1985). The fact that protein kinase $\mathrm{C}$ affects the 3 major phosphoproteins of GCPs, as well as several minor ones, suggests that this kinase plays a prominent role in growth cone function.

Further information on the nature of protein kinases in GCPs can be obtained by phosphoamino acid analysis of the substrates. In the 46 and $40 \mathrm{kDa}$ phosphoproteins, only P-Ser was detected in our assays. P-Tyr, not associated with either the $\mathrm{Ca}^{2+} / \mathrm{CM}$ - or $\mathrm{Ca}^{2+} /$ phospholipid-dependent kinase activities, was not detectable in the digests of GCP proteins phosphorylated under the conditions described in this study.

The evidence linking the activation of cell surface receptors and the breakdown of polyphosphoinositides with the stimulation of protein kinase C (cf. Lapetina et al., 1984; Nishizuka, 1984a; Fearon and Tashjian, 1985) prompted the examination of GCPs for phosphoinositides. If, upon binding of a ligand such as a growth factor to the growth cone membrane, polyphosphoinositides are rapidly formed and broken down, then GCPs would be expected to have, as intrinsic constituents, PI-kinase activity(ies). Accordingly, after phosphorylation reactions in $v i$ tro, the reaction product PIP $_{2}$ should be readily detectable. The finding of a radiolabeled, diffuse band below the dye front in SDS-PAGE, used to separate GCP phosphoproteins, suggested the presence of a phosphorylated lipid. A ${ }^{32} \mathrm{P}$-labeled lipid fraction extracted from phosphorylated GCPs was indeed found to comigrate with this band. More significantly, ${ }^{32} \mathrm{P}$-labeled components of this lipid extract comigrate with PIP and $\mathrm{PIP}_{2}$ when analyzed by thin-layer chromatography. The kinetics of the appearance of PIP and PIP $_{2}$ are very rapid, and the amounts of ${ }^{32} \mathrm{P}$ incorporated are high, comparable to those found in the major polypeptide substrates. This demonstrates the presence and the high level of activity of a PI-kinase in GCPs. 
Inositol trisphosphate $\left(\mathrm{IP}_{3}\right)$ is a degradation product, along with diacylglycerol (DAG), of receptor-activated PIP $_{2}$ cleavage by phospholipase (Thomas et al., 1984). DAG is known to activate protein kinase $\mathrm{C}$ (Kishimoto et al., 1980; Nishizuka, 1984b). IP ${ }_{3}$ release in GCPs can be stimulated with a factor derived from fetal brain; this will be the topic of a separate research report (Garofalo and Pfenninger, 1986). There is a rapidly growing body of evidence for the role of $\mathrm{IP}_{3}$ in the liberation of calcium from intracellular, nonmitochondrial stores (Streb et al., 1983; Gershengorn et al., 1984; Joseph et al., 1984; Suresh et al., 1984; Thomas et al., 1984; O'Rourke et al., 1985). This release is proposed as the mechanism for the rise in intracellular calcium levels in response to receptor binding. Following this rationale, it would be expected that $\mathrm{IP}_{3}$ would have a stimulatory effect on $\mathrm{Ca}^{2+}$-activated phosphorylation reactions in GCPs. In the saponin-permeabilized GCP system, at lowbuffered calcium concentrations $(0.1$ and $1 \mu \mathrm{M})$, exogenous $\mathrm{IP}_{3}$ was shown to stimulate the ${ }^{32} \mathrm{P}$ incorporation into pp40 and pp80ac C-kinase substrates. The $46 \mathrm{kDa}$ protein, a $\mathrm{Ca}^{2+} / \mathrm{CM}$ stimulated phosphorylation and C-kinase substrate, and a 52 $\mathrm{kDa}$ substrate, presumably tubulin, were not affected by exogenous $\mathrm{IP}_{3}$.

If calcium stores in GCPs were depleted by ionophore treatment prior to exposure with $\mathrm{IP}_{3}$, there was no longer a stimulatory effect of $\mathrm{IP}_{3}$ on phosphorylation in this system. This suggests that $\mathrm{IP}_{3}$ may stimulate C-kinase in GCPs via the release of calcium from an intracellular compartment. However, we do not know at present whether the selective activation of C-kinase is due to the particular experimental conditions used and represents the situation in vivo accurately. It is important to note that pp46 is different from pp80ac and pp40 in several respects. These differences include the fact that pp46 is a membrane (presumably plasmalemmal) protein, whereas the latter substrates are found in soluble GCP subfractions (Ellis et al., 1985; Katz et al., 1985). Thus, these substrates and/or their calcium/ CM- and C-kinascs may not be equally accessible to the intracellularly liberated calcium. Also, this calcium may be limited in its effect on the various kinases under the buffering conditions used in these experiments (omission of calcium buffering produces greatly variable results). Evidence for $\mathrm{IP}_{3}$ stimulation of phosphorylation of C-kinase substrates has been presented previously in the saponin-permeabilized platelet system (Lapetina et al., 1984; Watson et al., 1984).

The present data indicate that one of the growth cone's major developmentally regulated membrane proteins, pp46, is (directly or indirectly) phosphorylated by $\mathrm{Ca}^{2+} /$ calmodulin- and C-kinase, and that the PI pathway may be linked, probably causally to protein phosphorylation in GCPs. These components may function to transduce a humoral signal to an enzymatic cascade involving calcium-dependent protein phosphorylation in the growth cone. In view of the proposed role of polyphosphoinositide metabolism and C-kinase activity in growth regulation in other cell systems and in NGF activation of peripheral neurons, PI phosphorylation and breakdown and C-kinase activation in GCPs may be dependent on a CNS growthpromoting factor. The search for such a factor, i.e., an agonist for this $\mathrm{Pl} / \mathrm{C}$-kinase system, is in progress in this laboratory (cf. Garofalo and Pfenninger, 1988).

\section{References}

Anglister, L., I. Farber, A. Shahar, and A. Grinvald (1982) Localization of voltage-sensitive calcium channels along developing neurites:
Their possible role in regulating neurite elongation. Dev. Biol. 94 351-365.

Bennet, M. K., N. Erondu, and M. Kennedy (1983) Purification and characterization of a calmodulin-dependent protein kinase that is highly concentrated in brain. J. Biol. Chem. 258: 12735-12744.

Bradford, M. M. (1976) A rapid and sensitive method for quantitation of microgram quantities of protein utilizing the principle of proteindye binding. Anal. Biochem. 72: 248-254.

Campenot, R. B. (1977) Local control of neurite development by nerve growth factor. Proc. Natl. Acad. Sci. USA 74: 4516-4519.

Castagna, M., Y. Takai, K. Kaibuchi, K. Sano, U. Kikkawa, and Y. Nishizuka (1982) Direct activation of calcium-activated, phospholipid-dependent protein kinase by tumor-promoting phorbol esters. J. Biol. Chem. 257: 7847-7851.

Cheng, Y., and L. Chen (1981) Detection of phosphotyrosine-containing 34,000-dalton protein in the framework of cells transformed with rous sarcoma virus. Proc. Natl. Acad. Sci. USA 78: 2388-2392.

Davis, J. S., L. West, and R. Farese (1984) Effects of luteinizing hormone on phosphoinositide metabolism in rat granulosa cells. J. Biol. Chem. 259: 15028-15034.

Davis, R., and M. Czech (1984) Tumor-promoting phorbol diesters mediate phosphorylation of the epidermal growth factor receptor. J. Biol. Chem. 259: 8545-8549.

DeGraan, P. N. E., C. O. M. VanHooff, B. C. Tilly, A. B. Oestreicher, P. Schotman, and W. H. Gispen (1985) Phosphoprotein B-50 in nerve growth cones from fetal rat brain. Neurosci. Lett. 61: 235-241.

Drust, D., and T. Martin (1984) Thyrotropin-releasing hormone rapidly activates protein phosphorylation in $\mathrm{GH}_{3}$ pituitary cells by a lipid-linked, protein kinase C-mediated pathway. J. Biol. Chem. 259: 14520-14530.

Ellis, L., F. Katz, and K. H. Pfenninger (1985) Nerve growth cones isolated from fetal rat brain. II. Cyclic adenosine $3^{\prime}: 5^{\prime}$-monophosphate (cAMP)-binding proteins and cAMP-dependent protein phosphorylation. J. Neurosci. 5: 1393-1401.

Fairbanks, G., T. Steck, and D. Wallach (1971) Electrophoretic analysis of the major polypeptides of the human erythrocyte membrane. Biochemistry 10: 2606-2617.

Fearon, C., and A. Tashjian, Jr. (1985) Thyrotropin-releasing hormone induces redistribution of protein kinase $\mathrm{C}$ in $\mathrm{GH}_{4} \mathrm{C}_{1}$ rat pituitary cells. J. Biol. Chem. 260: 8366-8371.

Frackelton, A. R., Jr., P. Tremble, and L. Williams (1984) Evidence for the platelet-derived growth factor-stimulated tyrosine phosphorylation of the platelet-derived growth factor receptor in vivo. J. Biol. Chem. 259: 7909-7915.

Garofalo, R., and K. Pfenninger (1984) Characterization of phospholipid methyl-transferases in nerve growth cones from fetal rat brain. J. Cell Biol. 99: 419a.

Garofalo, R. S., and K. H. Pfenninger (1986) Phosphatidylinositol turnover in nerve growth cones isolated from the CNS. J. Cell Biol. 103: 454a.

Gershengorn, M. C., F. Geras, V. Spina, P. Urrello, and M. Rebecchi (1984) Inositol trisphosphate mediates thyrotropin-releasing hormone mobilization of nonmitochondrial calcium in rat mammotropic pituitary cells. J. Biol. Chem. 259: 10675-10681.

Greene, L., and E. Shooler (1980) The nerve growth factor: Biochemistry, synthesis and mechanism of action. Annu. Rev. Neurosci. 3: 353-402.

Gundersen, R., and J. Barrett (1980) Characterization of the turning response of dorsal root neurites toward nerve growth factor. J. Cell Biol. 87: 546-554.

Hama, T., K. P. Huang, and G. Guroff (1986) Protein kinase C as a component of a nerve growth factor-sensitive phosphorylation system in PC12 cells. Proc. Natl. Acad. Sci. USA 83: 2353-2357.

Hirata, F., K. Matsuda, Y. Notsu, T. Hattori, and R. Del Carmine (1984) Phosphorylation at a tyrosine residue of lipomodulin in mitogen-stimulated murine thymocytes. Proc. Natl. Acad. Sci. USA 81 : $4717-4721$.

Hyman, C., and K. H. Pfenninger (1985) Intracellular regulators of neuronal sprouting: Calmodulin binding proteins of nerve growth cones. J. Cell Biol. 101: 1153-1160.

Joseph, S. K., A. Thomas, R. Williams, and R. Irvine (1984) myoInositol 1.4.5-trisphosphate, a second messenger for the hormonal mobilization of intracellular $\mathrm{Ca}^{2+}$ in the liver. J. Biol. Chem. 259: 3077-3081

Katz, F., L. Ellis, and K. H. Pfenninger (1985) Nerve growth cones 
isolated from fetal rat brain. III. Calcium-dependent protein phosphorylation. J. Neurosci. 5: 1402-1411.

Kennedy, M. B. (1983) Experimental approaches to understanding the role of protein phosphorylation in the regulation of neuronal function. Annu. Rev. Neurosci. 6: 493-525.

Kennedy, M. B., T. McGuiness, and P. Greengard (1983) A calcium/ calmodulin-dependent protein kinase from mammalian brain that phosphorylates synapsin I: Partial purification and characterization. J. Neurosci. 3: 818-832.

Kikkawa, U., Y. Takai, R. Minakuchi, S. Inohara, and Y. Nishizuka (1982) Calcium-activated, phospholipid-dependent protein kinase from rat brain: Subcellular distribution, purification, and properties. J. Biol. Chem. 257: 13341-13348.

Kikkawa, U., Y. Takai, Y. Tanaka, R. Miyake, and Y. Nishizuka (1983) Protein kinase $\mathrm{C}$ as a possible receptor protein of tumor-promoting phorbol esters. J. Biol. Chem. 258: 11442-11445.

Kishimoto, A., A. Takai, T. Mori, J. Kikkawa, and Y. Nishizuka (1980) Activation of calcium and phospholipid-dependent protein kinase by diacylglycerol, its possible relation to phosphatidylinositol turnover. J. Biol. Chem. 255: 2273-2276.

Laemmli, U. K. (1970) Cleavage of structural proteins during the assembly of the head of bacteriophage T4. Nature 27: 680-685.

Lakshmanan, J. (1978) Nerve growth factor induced turnover of phosphatidylinositol in rat superior cervical ganglia. Biochem. Biophys. Res. Comm. 82: 767-775.

Lapetina, E. G., S. P. Watson, and P. Cuatrecasas (1984) myo-Inositol $1,4,5$ trisphosphate stimulates protein phosphorylation in saponinpermeabilized human platelets. Proc. Natl. Acad. Sci. USA 81: 74317435.

Lowry, O. H., N. J. Rosebrough, A. L. Fair, and R. J. Randall (1951) Protein measurement with the Folin phenol reagent. J. Biol. Chem. 193: 265-275.

Meiri, K. F., K. H. Pfenninger, and M. B. Willard (1986) Growthassociated protein, GAP-43, a polypeptide that is induced when neurons extend axons, is a component of growth cones and corresponds to pp46, a major polypeptide of a subcellular fraction enriched in growth cones. Proc. Natl. Acad. Sci. USA 83: 3537-3541.

Nelson, R. B., A. Routtenberg, C. Hyman, and K. H. Pfenninger (1985) A phosphoprotein (F1) directly related to neural plasticity in adult rat brain may be identical to a major growth cone membrane protein (pp46). Soc. Neurosci. Abstr. 11: 927.

Nemenoff, R. A., Y. Kwok, G. Shulman, P. Blackshear, R. Osathanondh, and J. Avruch (1984) Insulin-stimulated tyrosine protein kinase. J. Biol. Chem. 259: 5058-5065.

Nestler, E. J., S. Walaas, and P. Greengard (1984) Neuronal phosphoproteins: Physiological and clinical. Science 225: 1357-1364.

Niedel, J. E., L. Kuhn, and G. Vandenbark (1983) Phorbol diester receptor copurifies with protein kinase C. Proc. Natl. Acad. Sci. USA 80: $36-40$.

Nishizuka, Y. (1984a) The role of protein kinase C in cell-surface signal transduction and tumor promotion. Nature 308: 693-698.

Nishizuka, Y. (1984b) Turnover of inositol phospholipids and signal transduction. Science 225: 1365-1370.

O'Farrell, P. Z., H. Goodman, and P. O'Farrell (1977) High resolution two-dimensional electrophoresis of basic as well as acidic proteins. Cell 12: 1133-1142.

O'Rourke, F. A., S. Halenda, G. Zavoico, and M. Feinstein (1985) Inositol 1,4,5-trisphosphate releases $\mathrm{Ca}^{2+}$-transporting membrane vesicle fraction derived from human platelets. J. Biol. Chem. 260: 956-962.

Petruzzelli, L., R. Herrera, and O. Rosen (1984) Insulin receptor is an insulin-dependent tyrosine protein kinase: Copurification of insulin-binding activity and protein kinase activity to homogeneity from human placenta. Proc. Natl. Acad. Sci. USA 81: 3327-3331.
Pfenninger, K. H. (1986) Of nerve growth cones, leukocytes and memory: Second messenger systems and growth-regulated proteins. Trends Neurosci. 9: 562-565.

Pfenninger, K., and M. Johnson (1981) Nerve growth factor stimulates phospholipid methylation in growing neurites. Proc. Natl. Acad. Sci. USA 78: 7797-7800.

Pfenninger, K. H., L. Ellis, M. Johnson, L. Friedman, and S. Somlo (1983) Nerve growth cones isolated from fetal rat brain. I. Subcellular fractionation and characterization. Cell 35: 573-584.

Pike, L. J., D. Bowen-Pope, R. Ross, and E. Krebs (1983) Characterization of platelet-derived growth factor-stimulated phosphorylation in cell memibranes. J. Biol. Chem. 258: 9383-9390.

Rees-Jones, R., and S. Taylor (1984) An endogenous substrate for the insulin receptor-associated tyrosine kinase. J. Biol. Chem. 260: 44614467.

Rees-Jones, R. W., S. Hendricks, M. Quarum, and J. Roth (1984) The insulin receptor of rat brain is coupled to tyrosine kinase activity. $J$. Biol. Chem. 259: 3470-3474.

Rozengurt, E., M. Rodriguez-Pena, and K. Smith (1983) Phorbol esters, phospholipase $\mathrm{C}$, and growth factors rapidly stimulate the phosphorylation of a $M_{\mathrm{r}} 80,000$ protein in intact quiescent $3 T 3$ cells. Proc. Natl. Acad. Sci. USA 80: 7244-7248.

Skene, J. H. P., R. D. Jacobson, G. J. Snipes, C. B. McGuire, J. J. Norden, and J. A. Freeman (1986) A protein induced during nerve growth (GAP-43) is a major component of growth-cone membranes. Science 233: 783-786.

Streb, H., R. Irvine, M. Berridge, and I. Schulz (1983) Release of $\mathrm{Ca}^{2+}$ from a nonmitochondrial intracellular store in pancreatic acinar cells by inositol-1.4.5-trisphosphate. Nature 306: 67-69.

Sugimoto, Y., M. Whitman, L. Cantley, and R. Erikson (1984) Evidence that the rous sarcoma virus transforming gene product phosphorylates phosphatidylinositol and diacylglycerol. Proc. Natl. Acad. Sci. USA 81: 2117-2121.

Suresh, K., S. Joseph, R. Williams, B. Corkey, F. Matchinsky, and J. Williamson (1984) The effect of inositol trisphosphate on $\mathrm{Ca}^{2+}$ fluxes in insulin-secreting tumor cells. J. Biol. Chem. 259: 12952-12955.

Thomas, A. P., J. Alexander, and J. Williamson (1984) Relationship between inositol polyphosphate production and the increase of cytosolic free $\mathrm{Ca}^{2+}$ induced by vasopressin in isolated hepatocytes. $\mathrm{J}$. Biol. Chem. 259: 5574-5584.

Traynor, A. E. (1984) The relationship between neurite extension and phospholipid metabolism in PC12 cells. Dev. Brain Res. 14: 205210 .

Ushiro, H., and S. Cohen (1980) Identification of phosphotyrosine as a product of epidermal growth factor-activated protein kinase in A-431 cell membranes. J. Biol. Chem. 255: 8363-8365.

Vilgrain, I., C. Cochet, and E. Chambaz (1984) Hormonal regulation of a calcium-activated, phospholipid-dependent protein kinase in bovine adrenal cortex. J. Biol. Chem. 259: 3403-3406.

Watson, S. P., R. McConnell, and E. Lapetina (1984) The rapid formation of inositol phosphates in human platelets by thrombin is inhibited by prostacyclin. J. Biol. Chem. 259: 13199-13203.

Weber, K., and M. Osborn (1969) The reliability of molecular weight determinations by dodecyl-sulfate-polyacrylamide gel electrophoresis. J. Biol. Chem. 244: 4406-4412.

Williamson, J. R., R. Cooper, S. Joseph, and A. Thomas (1985) Inositol trisphosphate and diacylglycerol as intracellular second messengers in liver. Am. J. Physiol. 248: C203-C216.

Yano, K., H. Higashida, R. Inoue, and Y. Nazawa (1984) Bradykinininduced rapid breakdown of phosphatidylinositol 4,5-bisphosphate in neuroblastoma $\times$ glioma hybrid NG108-15 cells. J. Biol. Chem. 259: 10207. 